\title{
TÜRK YER ADLARI
}

\section{Keçiborlu}

\section{HASAN EREN}

1. Bundan birkaç yıl önce Keçiborlu ağzı üzerinde çalışan bir öğrencime bu güzel kasabanın adının nereden geldiğini sordum. Keçiborlu'da yetişmiş ve bu çevrede birtakım dil ve folklor araştırmaları yapmış olan öğrencim, yerli halkın, bu adın Türkçe keçi kelimesinden geldiğine inandığını söyledi. Halkın bu inancına katıldığı anlaşılan öğrencime göre, Keçiborlu çevresinde koyun yerine daha çok keçi beslenirmiş.

Keçiborlu çevresinde daha çok keçi beslendiğine göre, Keçiborlu adının Türkçe keçi kelimesinden geldiği inancının sağlam bir gözleme dayandığı ileri sürülebilir. Ancak, benim fikrime göre, Keçiborlu çevresinde keçi yetiştirilmesi, bu adın Türkçe keçi kelimesinden geldiğini ispat edemez.

2. Keçi, koç, koyun, kuzu, oğlak, öveç, teke, toklu... gibi kelimelerin yer adlarımızda sık sık kullanıldığını biliyoruz. İşte birkaç örnek:

1. Keçiağılı (Bolu, Çanakkale), Keçibel (Sivas), Keçibükü (Muğla), Keçiçalı (Samsun), Keçidere (Balıkesir), Keçideresi (Zonguldak), Keçikaya (Bursa, Çanakkale), Keçikıran (Bolu), Keçiler (Gaziantep), Keçiler (Bursa), Keçili (Afyon, Amasya, Ankara, Burdur, Çanakkale, Isparta, İzmir, Manisa, Muğla, Sivas, Urfa), Keçioğlu (Çankırı, Sinop, Zonguldak), Keçiören (Ankara), Keçipazar (Konya), Keçipınarı (Muğla), Akkeçili (Afyon, İzmir, Manisa), Akçakeçili (Çanakkale), Karakeçili (Ankara, Çorum, Manisa).

2. Koçalan (Amasya, Samsun), Koç̧ukur (Giresun), Koçköprï (Sivas), Koçkuyu (Konya), Koçlu (Trabzon), Koçoğlu (Bahkesir, Samsun), Koçoluk (Hatay), Koçseki (Kastamonu), Koçtepe (Giresun), Karakos (Kastamonu, Kırklareli, Sivas, Zonguldak), Karakoçlu (Zonguldak). 
3. Koyunağıl (Eskişehir), Koyunağılı (Çorum), Koyunalan (Giresun), Koyuncu (Amasya, İçel, Manisa, Sivas), Koyuncular (Aydın), Koyunçalı (Afyon), Koyundere (Bursa, İzmir, Manisa), Koyuneli (İzmir), Koyuneri (Bahkesir), Koyunevi (Çanakkale), Koyunkaya (Sivas), Koyunkuran (Kastamonu), Koyunlar (Aydın), Koyunlu (Bilecik, Samsun), Koyunoba (Kütahya), Koyunoğlu (Çorum, Sivas), Koyunpınar (Eskişehir), Koyuntepe (Edirne), Koyunyeri (Çanakkale, Edirne), Akkoyun (Ankara), Akkoyunlu (Afyon), Akçakoyun (Bursa, Çanakkale, Çorum), Akçakoyunlu (Çorum, İçel), Karakoyun (Muğla, Sinop, Urfa), Karakoyunlu (Ankara, Antalya, Çankır, Kayseri, Ordu).

4. Kuzucu (Edirne, İçel, Konya), Kuzucubelen (İçel), Kuzucular (Ankara), Kuzuculu (Hatay), Kuzuçardağı (Kırklareli), Kuzuderesi (Aydın), Kuzular (Bilecik, Samsun), Kuzuluçukur (Hatay), Kuzuluk (Çorum, Giresun, Sinop, Sivas), Akkuzulu (Ankara, Samsun, Sivas), Karakuzu (İzmir, Urfa).

5. Oğlakçı (Ankara, Eskişehir, Tokat, Urfa), Oğlakçılar (Sinop), Oğlakkaya (Kayseri), Bozoğlak (Kastamonu), Kizaloğlak (Samsun).

6. Öveçağılı (Niğde), Övę̧ler (Kastamonu), Övę̧li (Manisa).

7. Teke (Çanakkale, Burdur, İzmir, Samsun, Trabzon), Tekeciler (Bursa), Tekedere (Izmir), Tekederesi (Erzurum, Malatya), Tekeler (Aydın, İçel, Kastamonu, Manisa), Tekeli (Aydın, Giresun, İçel, Kocaeli, Sivas), Tekelioğlu (Manisa), Tekeoğlu (Kastamonu), Tekeoynağ - (Sinop), Tekepınarı (Denizli), Karateke (Denizli, İzmir, Muğla), Karatekeli (İzmir).

8. Tokluağıl (Giresun), Tokluargacı (Niğde), Toklucak (Afyon, Kayseri), Toklular (Antalya), Kizzlcatoklu (Samsun).

Keçi, koç, koyun, kuzu ... kelimeleriyle yapılmış olan yer adlarının çokluğuna rağmen, Keçiborlu adının birinci bölümü, 'eti, sütü, kılı ve derisi için yetiştirilen evcil hayvan (Capra hircus)' anlamma gelen keçi kelimesiyle birleştirilemez, sanıyorum.

Bu güzel kasabanın adı Türkçe keçi kelimesinden gelseydi, çevresinde keçi yerine daha çok koyun yetiştirilen başka bir köy veya kasabaya Koyunborlu adının verilmesi gerekirdi. Oysa benim bildiğime göre, yurdumuzda buna benzer bir yer adı yoktur. Buna karşılık, Isparta ilinde Uluborlu adlı bir ilçe bulunduğunu biliyoruz. Keçiborlu adını açıklarken Uluborlu adını da göz önünde tutmak şarttır. 
Uluborlu yer adının Türkçe 'büyük' anlamında kullanılan ulu kelimesinden geldiği açıktır: Ulu Borlu 'Büyük Borlu'.

Türkçe $u l u$ kelimesi yer adlarında sık sık kullanılan bir sıfattır. Ulualan (Muğla), Ulubey (Kütahya), Uluçal (Samsun), Uluçayır (Eskişehir, Samsun), Uluçukur (Sivas), Uludere (Eskişehir), Ulugeçit (Zonguldak), Ulugöl (Antalya, Sivas), Ulukavak (Çorum), Ulukışla (Niğde), Ulukoz (Zonguldak), Uluköy (Afyon;- Ankara, Çankırı, Denizli, Giresun, Kastamonu, Samsun, Sinop)... gibi.

Uluborlu adındaki ulu kelimesi gibi, Keçiborlu adındaki keçi (kiçi) kelimesi de bir sıfattır. Bu yer adındaki keçi kelimesi bir ad (isim) olsaydı, bu adın Keçiborlusu biçimini alması beklenirdi. Oysa buna benzer bir biçim tesbit edilmemiştir. Buna göre, Keçiborlu adındaki keçi kelimesi bir sıfattır. Bu sebeple, Keçiborlusu diye bir biçimin kullanılmaması normaldir.

Bu duruma göre, Keçiborlu adının keçi kelimesiyle birleştirilmesi bir halk etimolojisinden başka bir şey değildir. Keçiborlu çevresinde koyun yerine daha çok keçi yetiştirilmesi, eski Türkçe kiçi (kiçig) kelimesinin keçi'ye çevrilmesini kolaylaştırmıştır. 1971 yazında Keçiborlu çevresinde keçi sürülerinin çokluğunu gördüm. Buna rağmen, Keçiborlu adının keçi ye dayandığı ileri sürülemez. Yalnız Kiçiborlu adının çevredeki keçilerin çokluğu dolayısiyle Keçiborlu biçimine girdiği açıktir.

3. Yer adlanmızda aynı adı taşıyan köy veya kasabalan birbirinden ayırmak için büyük : küçük, aşağı : yukarı, eski : yeni ... gibi birtakım sıfatlar kullanılır. Büyük Çekmece : Küçük Çekmece (İstanbul), Eski Polatlı: Polatlı (Ankara), Aşağı Ayrancı: Yukarı Ayrancı (Ankara) gibi.

Eskiden yer adlarımıda büyük : küçük sıfatları yerine $u l u$ : kiçi sıfatları kullanılmıştır. Ulu Borlu : Kiçi Borlu gibi. Sonradan Ulu Bor$l u$ (Uluborlu) adıyle Kiçi Borlu (Kiçiborlu) adı arasındaki birlik bozulmuş, Kiçiborlu adı halk etimolojisiyle Keçiborlu biçimine girmiştir.

Ulu Borlu : Kiçi Borlu adları arasındaki ilişkiye benzer güzel bir örnek verilebilir: Konya ilinde Sille bucağında Ulumuhsine (Ulu Muhsine) adlı bir köy vardır. Bu köyün küęük mahallesine Kiçimuhsine 
(Kiçi Muhsine) adının verilmesi gerekirdi. Oysa halk arasında Kiçi Muhsine adı Keçimuhsine biçimini almıştır. Kiçi Borlu adının Keçiborlu biçimine sokulması gibi. ${ }^{1}$

1 Bu yazıyı yazdıktan sonra F. Aksu'nun Isparta ili yer adlan (Isparta, 1936) adlı küçük eserinde (10. s. 15. not) Keçiborlu adı üzerinde durduğunu gördüm. Aksu'nun bu yoldaki notunu olduğu gibi ahyorum: "Kasaba, ovaya açlan ve (Tülü) denen bir boğazın önündedir. Köyleriyle beraber 13600 nufuslu, ağaçhk bir kasabadır. Işleyen zengin bir Kükürt madeni vardır. Alçı bulunduğu da söylenir. Keçi, küçük ve Bor Gayri münbit, Tebeşir, Alçı taşı, Çukur, Şarap, Kurat gibi çeşitli anlamlar taşur."

Aksu, bu notunda Keçiborlu adındaki keçi'nin 'küçük' demek olduğunu belirtmişse de, Uluborlu : Keçiborlu adlan arasındaki bağlantıya değinmemiştir. 